\title{
Adapting to climate change through local municipal planning: barriers and challenges
}

\author{
Thomas G. Measham • Benjamin L. Preston • \\ Timothy F. Smith • Cassandra Brooke • \\ Russell Gorddard • Geoff Withycombe • Craig Morrison
}

Received: 6 January 2011 / Accepted: 13 May 2011 /

Published online: 26 May 2011

(C) The Author(s) 2011. This article is published with open access at Springerlink.com

\begin{abstract}
Municipal planning represents a key avenue for local adaptation, but is subject to recognised constraints. To date, these constraints have focused on simplistic factors such as limited resources and lack of information. In this paper we argue that this focus has obscured a wider set of constraints which need to be acknowledged and addressed if adaptation is likely to advance through municipal planning. Although these recognised constraints are relevant, we argue that what underpins these issues are more fundamental challenges affecting local, placed-based planning by drawing on the related field of community-based environmental planning (CBEP). In considering a wider set of constraints to practical attempts towards adaptation, the paper considers planning based on a case study of three municipalities in Sydney, Australia in 2008. The results demonstrate that climate adaptation was widely accepted as an important issue for planning conducted by local governments. However, it was yet to be embedded in planning practice which retained a strong mitigation bias in relation to climate change. In considering the case study, we draw attention to factors thus far under-acknowledged in the climate adaptation literature. These include leadership, institutional context and competing planning agendas. These factors can serve as constraints or enabling mechanisms for achieving climate adaptation depending upon how they are exploited in any given situation. The paper concludes that, through
\end{abstract}

T. G. Measham $(\bowtie) \cdot$ R. Gorddard

CSIRO Ecosystem Sciences, GPO Box 284, Canberra, ACT 2601, Australia

e-mail: Tom.Measham@csiro.au

B. L. Preston

Oak Ridge National Laboratory, P.O. Box 2008, Oak Ridge, TN 37831, USA

T. F. Smith

University of the Sunshine Coast, Locked Bag 4, Maroochydore DC, QLD 4558, Australia

C. Brooke

WWF-Australia, PO Box 528, Sydney, NSW 2001, Australia

G. Withycombe $\cdot$ C. Morrison

Sydney Coastal Council Group, GPO Box 1591, Sydney, NSW 2001, Australia 
addressing these issues, local, place-based planning can play a greater role in achieving climate adaptation.

Keywords Community engagement $\cdot$ Institutional capacity $\cdot$ Local adaptation $\cdot$ Place-based planning $\cdot$ Sydney Australia

\section{Introduction}

Recent years have witnessed rapidly increasing attention to adaptation to the 'unavoidable' impacts of climate change (NCCARF 2010; Preston et al. 2011). The rapid development of adaptation as a mainstream strategy for addressing climate vulnerability is evidenced by a broad range of emergent adaptation policy developments. At the international level, a variety of adaptation finance mechanisms have been established through the UNFCCC and/or the Kyoto Protocol more specifically including the Global Environment Facility Trust Fund, the Special Climate Change Fund, the Least Developed Countries Fund, and the Adaptation Fund. These mechanisms are complimented by a range of other multi-lateral arrangements for adaptation finance. At the national level, developing nations have completed National Adaptation Programs of Action (NAPAs) that are intended to be frameworks for prioritizing adaptation needs. Developed nations have also commenced a range of national adaptation initiatives including efforts to deliver climate information and projections, the development of adaptation guidance, institutional adaptation strategies and plans (CEC 2007; COAG 2007; Swart et al. 2009; DCCEE 2010; NRC 2010).

While historically, adaptation planning and policy has been focused largely at the national scale, such as through NAPAs (Agrawal 2008; Tompkins 2005), attention to adaptation at the local level has proliferated rapidly in recent years. This emphasis on local adaptation stems from a number of sources. First, it reflects the prevailing opinion in the adaptation literature that 'adaptation is local'. The impacts of climate change are experienced locally, and therefore, geographic variability in climate impacts emphasises the need for 'place-based' approaches to climate vulnerability analysis and adaption (Adger and Kelly 1999; Cutter et al. 2000; Turner et al. 2003). The term 'place-based' refers to a spatially distinct group of bio-physical and social conditions, which can, in principle, occur at any scale but tend to focus at local and regional scales where global and local drivers manifest themselves in particular ways (Walker et al. 2002; Turner et al. 2003). In addition, local governance systems are often the responsible and legitimate entity for managing such impacts. For example, Agrawal (2008) argues that local institutions have three critical roles in climate adaptation, namely 1) structuring responses to local impacts; 2) mediating between individual and collective responses to vulnerability; and 3) governing the delivery of resources to facilitate adaptation. The second driver of local adaptation is a perceived lack of progress at international and national scales to secure significant reductions in greenhouse gas emissions. Hence, local organizations are seeking pathways by which they can be empowered to respond to climate change in a manner that yields local benefits.

At the local scale, municipalities (also known as local governments) represent a core institutional unit that are increasingly recognized as having a critical role to play in climate adaptation (Naess et al. 2005; Smith et al. 2009; DCCEE 2010). This is perhaps best evidenced by the evolution of adaptation initiatives and policy in Australia. Since approximately 2005, Australia's federal government has pursued a range of initiatives to 
build capacity regarding climate change impacts and adaptation options for local government. This has included multiple research and assessment initiatives, guidance for local government regarding methods for undertaking climate change risk assessments (AGO 2006), and the identification of adaptation options that might be applied at the local scale (DCCEE 2010). These initiatives have led to the proliferation of climate change risk assessment and adaptation planning by Australia's local governments (Preston and Kay 2010). Australia's efforts are mirrored in other parts of the world including Canada, New Zealand, and the UK (ME 2008; DCLG 2010; Richardson 2010; Smith et al. 2010). The World Mayors Council was launched in 2005 to promote international cooperation on climate change including an annual forum on adaptation. Meanwhile, adaptation science and practice have promoted the concept of community-based adaptation, which is locally focused, participatory, and draws on the normative preferences and knowledge of local people (Ebi and Semenza 2008; Reid et al. 2009). Non-governmental organisations are also concentrating efforts at the local scale. The International Council for Local Environmental Initiatives (ICLEI), for example, has engaged in developing adaptation guidance and practice in a range of global regions including North America and Oceania with a particular emphasis on urban areas (Snover et al. 2007; ICELI Oceania 2008; ICLEI Canada 2010).

While the interest in local adaptation planning and policy highlights the relevance of local government for adaptation, its ultimate role with respect to practical implementation of policies and measures is dependent upon other actors within the governance network (Smith et al. 2009; Boydell 2010; Dovers and Hezri 2010). This raises questions regarding the extent to which the mantra that 'adaptation is local' truly applies when examined through the lens of governance. Local government, like other institutions, operates within an 'institutional void' (Hajer 2003; Hajer and Versteeg 2005), where the complexity of governance poses challenges to clear definitions of institutional roles and responsibilities, resulting in ineffectual policy development. Crabbé and Robin (2006) comment that the issue of climate change appears 'distant and cloudy' amongst an already crowded agenda of demands placed on local government by concerned citizens. Even in a single locality, the mandate of municipalities frequently extends from aesthetics to infrastructure, from parking to waste management (Wild River 2006; Pini et al. 2007). Furthermore, the mandate of local government is expanding, due to the shifting of responsibility from higher levels of authority to lower levels of authority, particularly from state and provincial authorities (Ivey et al. 2004). Such constraints to action may explain why the apparent interest in adaptation and adaptation planning hasn't necessarily translated into the implementation of actions to reduce vulnerability (Repetto 2008; Ford et al. 2011; Berrang-Ford et al. 2011; Preston et al. 2011).

In this paper our goal is to explore constraints to adaptation specifically in the context of local government, based on literature review and a case study involving three municipalities in Sydney, New South Wales, Australia. We first summarize the roles and responsibilities of local government in Australia, with particular emphasis on planning functions as the key adaptation-relevant responsibility of local government. Next, we outline the constraints on planning as a mechanism for adaptation that have been recognised in the climate change literature. We then turn to the conceptual sibling and longer established body of literature concerned with community-based environmental planning in order to demonstrate a wider set of constraints that are known to affect planning processes when incorporating community involvement. We subsequently present an empirical study of the constraints on planning for climate adaptation as identified by local government participants, and discuss the findings focusing on the political nature of local planning in practice as well as its linkages to the broader context of adaptation governance in Australia. 


\subsection{The role of Australian local government in adaptation}

Australia's formal government system is comprised of three hierarchical levels: federal, state, and local. As such, local government is both the level of government that is most commensurate with the scale at which climate change is experienced and that which is most readily accessible by civil society. Local government is charged with a range of roles and responsibilities (Smith et al. 2009; DCCEE 2010), which have evolved over time with the evolution of the broader governance system. Some of these functions are regulatory in nature, particularly those associated with the approval of development, redevelopment or other modifications to the community landscape and built environment. This regulatory authority influences spatial planning, business activity and commerce, and is a core element of local government risk management. However, local government is also responsible for providing a diverse array of non-regulatory services including storm water management, community education, public health fire prevention, recreation, taxation, and enforcing statutory regulations on behalf of higher governments. These other responsibilities also have important implications for adaptation. The manner in which they are pursued varies among councils depending upon size, geography, the various assets and activities that occur within councils, and the legislative mandates codified in state government legislation.

In the context of climate change, this diversity of responsibilities creates a number of challenges. Local governments have responsibility, (often shared with state governments) for both identifying potential natural hazards, including those associated with climatic events, and for ensuring that consideration of such hazards is incorporated into statutory and non-statutory local government decision-making. As such, there is a 'duty-of-care' within local government to ensure that development decisions do not create the potential for significant, unmanaged exposure to hazards. While this has long been a responsibility of local government, climate change has complicated this process by forcing municipalities to consider not only historical climate variability but also future climate change. Yet there is currently a general lack of either legislative directive or community best practice for how to incorporate climate risk and its uncertainties into local decision-making. This process, which necessitates learning, investment of resources, and policy development, must occur while local government fulfils the range of existing responsibilities. As such, climate adaptation is currently competing for space on the policy agenda as thus the budget of local government.

Perhaps the most crucial policy tools available to local government for driving adaptation to climate change are planning powers, which ultimately guide the execution and delivery of statutory and non-statutory powers and services. The rationale for local government's function of planning authority stems in part from its more direct interface with the public, and in part due to the subsidiarity principle, which argues for the smallest relevant scale of responding to a given challenge. Hence, local government has been argued to be the most salient political actor when responding to the locally specific manifestations of climate impacts, such as sea level rise or heat waves affecting any given community (Crabbé and Robin 2006). For example, out of five adaptation strategies reviewed by Tompkins and Adger (2004), some form of planning is central to three, namely urban planning to avoid the impacts of climate related hazards such as floods and heat stress, planning for demographic and consumption transition, and planning for ecosystem conservation.

It is also important to note that placed-based local government planning (not only for adaptation) occurs in two distinct modes. The first is strategic planning processes, 
which are important but not unique to local governments (Selman 1999). At the local scale, such strategic planning fosters community vision, aspirational goals and connection to place, along with defining pathways to achieve these goals. The second form is land-use planning, which is focused on the allocation of space to balance economic prosperity with acceptable living standards and the conservation of natural resources (Selman 1996). Although these two types of planning are quite different in practice, and in many cases are managed by different departments, we propose that both are highly important to climate change adaptation and contribute to achieving adaptation at the local scale.

Ultimately, however, the roles and responsibilities granted to local government are designated by state government (Adger 2003; Smith et al. 2009). For example, the Government of New South Wales' Local Government Act 1993, which is the principle legislation establishing the authority of local government, states, "all functions of a council come from statute, either from this Act or another Act." This statement alludes to the fact that a broad range of additional and overlapping legislation further defines the role of local government with respect to specific aspects of governance, such as planning, natural resources management, and coastal management (Smith et al. 2009). In many instances, such legislation has yet to incorporate future climate change, which subsequently affects the legal mandate of local government to adapt. This phenomenon of local authorities acting as implementing agents for higher levels of government is typical of local government in general. In Norway for example, it is reported that local institutions have few incentives for pro-active management. However, even within the role of an implementation agent, local institutions still have 'room to manoeuvre' and take decisions quickly when opportunities (or threats) arise (Critchley and Scott 2005; Naess et al. 2005). Hence, the legislative link between local and higher levels of government constrain local government to either undertake those actions that can be justified under existing responsibilities or to engage with the broader governance network to establish the necessary institutional arrangements in the development of new policies and measures (Adger 2003).

\section{Constraints recognised by the adaptation literature}

Practical experience of climate adaptation through local planning has a relatively short history in the adaptation literature. Thus it is not surprising that in the climate change literature, the constraints on local adaptation planning have tended to be conceptualised in a relatively straight-forward, mechanical way, emphasising the importance of inadequate information, institutional limitations, lack of resources and a culture of reactive management. These are summarised in turn.

\subsection{Lack of information}

Access to information pertaining to the vulnerability of municipalities to climate impacts has been reportedly scarce in both urban and rural locations (Mukheibir and Ziervogel 2007; Crabbé and Robin 2006). Due to the lack of reliable climate forecasts and predictions, scenarios have been used to assist climate adaptation planning, drawing on IPCC assessments, particularly at the national and state (provincial) scale (Dessai et al. 2005). A key point is that the degree of information needed for planning depends upon the type of adaptation being considered. Furthermore it needs to be pertinent to 
politicians, planners and managers, at a relevant scale and timeframe for taking action, so that local governments can determine what it is they have to plan for (Amundsen et al. 2010).

\subsection{Institutional limitations}

Another recognised constraint on the ability of local institutions to adapt to climate change through planning concerns their institutional context. The policy framework in which local government operates is largely imposed by higher levels of governance, such as provincial, state and national policies. Indeed, in many cases, municipal authorities have no constitutional standing of their own. Rather they are the delegated agents of a higher power such as a state in Australia (Wild River 2006) or a province in the case of Canada (Ivey et al. 2004). Hence for example in Sydney, a key planning mechanism known as Local Environmental Plans, prepared by individual councils, are a provision of the New South Wales Environmental Planning and Assessment Act 1979 (s53), and the State Minister for Planning is not bound by these plans, for example when considering state infrastructure projects.

\subsection{Resource constraints}

Municipalities are frequently highly constrained in terms of their financial capacity (Pini et al. 2007). In part this stems from the wide range of activities in which they are engaged. It is also due to their lack of institutional autonomy as already described. This lack of resources has been linked to reactive management of facilities and infrastructure. Municipal authorities are frequently tasked with managing state or province infrastructure, in addition to local infrastructure, yet their lack of authority and stressed resources inhibits effective life-cycle planning (Brackertz and Kenley 2002). These resource constraints can lead to self-perpetuating short-term technical fixes rather than long-term integrated approaches to addressing problems (Crabbé and Robin 2006).

\section{Lessons for local adaptation from community-based environmental planning}

While the history of local adaptation planning is relatively short, there is a much longer history of local planning on which to draw lessons. Community-based environmental planning (CBEP) presents a much more nuanced set of challenges affecting planning at the local and regional scale (Measham and Lane 2010). This field has long had a focus on 'place-based' environmental management, focusing attention on the unique suite of characteristics that constitute a problem context for planning, in a similar way to that proposed by Turner et al. (2003). A number of advantages and disadvantages of this type of planning have been recognized, and are relevant to current debates on climate adaptation.

Due to its focus on place, CBEP has been recognized as more sensitive to the local characteristics of a given environmental problem. Essentially, local, place-based communities are thought to be more familiar with their own particular challenges and thus better able to inform an appropriate planning process (Lane and McDonald 2005; Li 2002). On the basis of developing local 'ownership' of problems, CBEP is thought to lead to more legitimate processes than top-down planning which can isolate some stakeholders due to externally generated interests (Scott 1998). In principle this more sensitive and legitimate process leads to more effective outcomes (Measham and Lane 2010). While the notion of 
locally sensitive place-based planning is sound in principle, there are multiple problems with this mode of planning in practice. The first of these is that, even for discrete and localized communities, the range of stakeholder interests is highly heterogeneous and does not lend itself to consensus (Agrawal and Gibson 1999). The difficulty in reaching consensus is not only concerned with defining desired outcomes. Indeed, a major barrier to local environmental planning has been lack of community agreement over problem formation (Selman 1999).

A major challenge with place-based planning stems from overly simplistic notions of community. Naïve conceptions of community imply a homogenous, spatially fixed social group that shares a consciousness of being. Yet planning theorists emphasise that a multiplicity of communities exist, differentiated (and frequently divided) by factors including gender, ethnicity, class, and age (Lane and Corbett 2005). This complexity poses multiple challenges for adaptation planning, in terms of what adaptation means for different groups, who benefits and loses from adaptation, and above all, how to define legitimate adaptation options.

A key aim of CBEP has been to enable the integration of local, experiential knowledge with scientific knowledge. However, in practice this has rarely been achieved due to differences in competing knowledges that may not be reconciled in a single planning process. Finally, CBEP has been criticized for the potential for parochial thinking to dominate, with the possibility that strategies which seem appropriate at one scale can have harmful effects at other scales (Lane and McDonald 2005). This issue needs particular attention in the case of climate adaptation planning, because what may be considered reasonable adaptation for one community may have maladaptive effects for others (Adger et al. 2009).

\section{Adaptation and local planning in Sydney}

Based on the recognised constraints noted in the adaptation planning literature, and the wider lessons from CBEP, the authors developed a research project with the aim of identifying how local governments experience these constraints and how they address them in practical terms.

\subsection{Background}

The research presented in this paper formed part of a broader project called 'A Systems Approach to Regional Climate Change Adaptation Strategies in Metropolises' conducted from 2007-2009. This project was a partnership between the CSIRO Climate Adaptation Flagship, The University of the Sunshine Coast and the Sydney Coastal Councils Group. The latter represents the 15 coastal municipal councils in the Sydney region.

The project was developed in response to the need for practice-relevant research to build capacity in local governments to understand and address climate vulnerability at the local scale, in this case in Sydney Australia (Preston et al. 2009; Shaw et al. 2009; Moser 2010). The project involved three components. The first was an extensive mapping process to help council staff and elected officials to visualise vulnerability (Preston et al. 2008). The second was a series of workshops to consider vulnerability relative to different council responsibilities and activities (Smith et al. 2008b). The third phase involved case studies focusing on key adaptation barriers identified through the workshops (Smith et al. 2008a). These barriers related to a) infrastructure b) community attitudes and c) planning processes. The latter is the subject of this paper. 


\subsection{Method}

The data consist of in-depth interviews conducted in 2008 with staff from three municipal councils from across the Sydney region: Mosman, Leichhardt and Sutherland (Fig. 1). The three councils were selected to reflect diversity in terms of their size, demographic profile and location within Sydney, and their relative vulnerability to different types of impacts (Table 1). A total of 33 participants from these three councils took part in the interviews: (12, 11 and 10 from each respectively). Rather than speak only to planners, the research design made a deliberate effort to invite participants from a cross-section of council roles and responsibilities including elected leaders, senior managers, town planners, environmental managers, engineers and social planners. The rationale for this wider selection of participants is that climate adaptation requires an integrated approach.

The interview questions focused on the context, structure, process and outcomes of planning, in addition to some more general questions about the role of local government in relation to climate adaptation:

Fig. 1 Location of participating councils

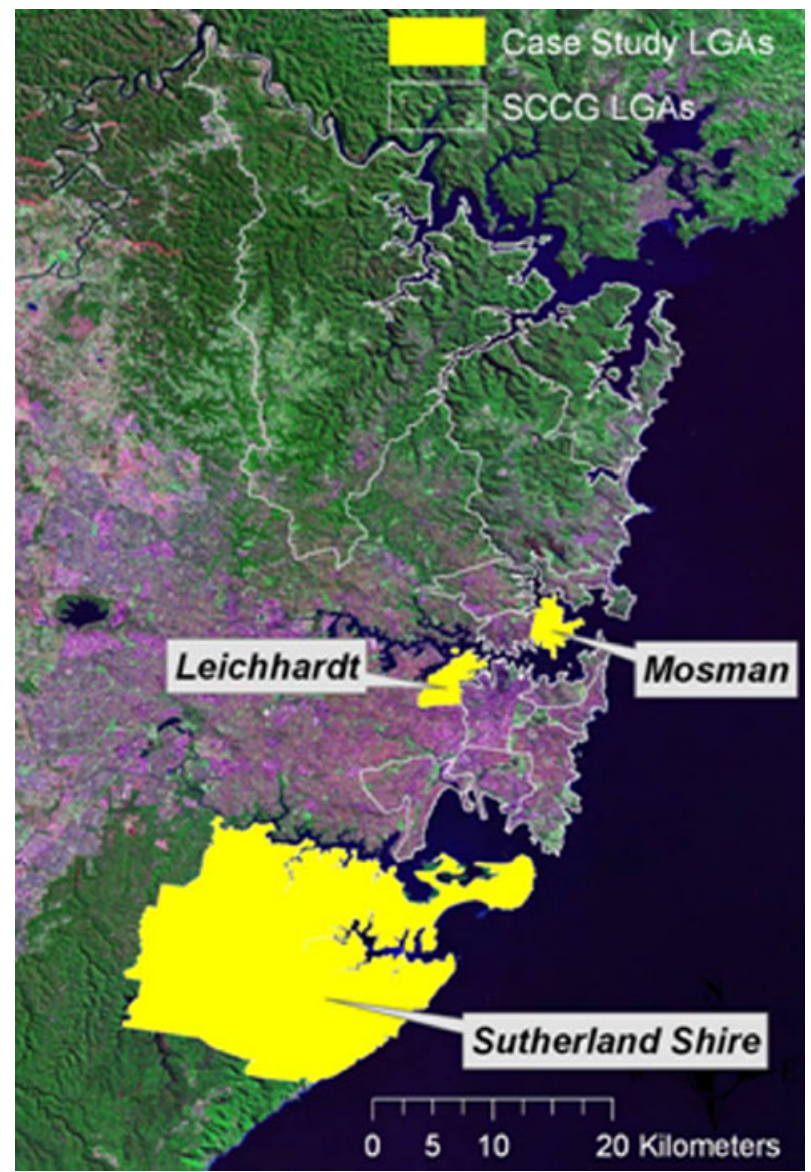


Table 1 Characteristics of case study councils

\begin{tabular}{llll}
\hline & Leichhardt & Mosman & Sutherland \\
\hline $\begin{array}{l}\text { Social characteristics* } \\
\text { Population }\end{array}$ & 51,554 & 27,737 & 212,531 \\
Average individual income & $\$ 66,014$ & $\$ 111,507$ & $\$ 46,353$ \\
\% Population 65 years and over & 9.3 & 14.8 & 13 \\
\% population 4 yrs and under & 6.9 & 6 & 6.4 \\
\% male / female & $47.9 / 52.1$ & $46 / 54$ & $49.2 / 50.8$ \\
$\%$ with Tertiary Education & 70.9 & 73.3 & 59.6 \\
\% Speaks language other than English at home & 15 & 11.1 & 10.9 \\
$\%$ population born overseas & 29.7 & 32.4 & 17.5 \\
Persons/km ${ }^{2}$ & 5,193 & $3,306.6$ & 664.2 \\
Relative vulnerability to different climate impacts & & & \\
Extreme heat & & Medium & Low \\
Sea level rise & High & Low & Medium \\
Extreme rainfall & High & High & Medium \\
Bushfire (wildfire) & High & Low & Medium \\
\hline
\end{tabular}

* 2006 Australian Bureau of Statistics Cat. 1379.0.55.001

${ }^{a}$ Relative vulnerability compared within Sydney Coastal Council Region summarised from Table 11 in Preston et al 2008, p 59

- What role does local government currently play in adapting to climate change?

- To what extent is climate change accepted as an issue for planning?

- Is climate change embedded in council plans and policies?

- How do you operationalize policies about climate change?

- How do you plan for uncertainty?

- How do you measure success in relation to planning for climate change?

- What are the signs of successful adaptation?

- Overall, what role should local government play in adapting to climate change?

- Overall, what would local councils need to do differently in order to effectively adapt to climate change?

The interviews were conducted and recorded by three researchers, each an author of this paper. All interviews took place on site at council offices and lasted between 30 min and $1 \mathrm{~h}$. The analysis involved grouping the responses into qualitative themes with the assistance of NVivo (QSR 2010) software. Each researcher analysed all the data individually at first then compared their themes with those of the other researchers to reach a shared representation of the data. Not all of the interview themes were directly relevant to the focus of this paper, so some tangential themes have been removed. Further information on the methods and the full set of empirical results are presented in Smith et al. (2008a).

\section{Results}

A summary of the interview questions by council is presented in Table 2. The results emphasise a strong mitigation bias through acts such improving energy efficiency of buildings, street lighting and installation of small energy cogeneration plants. Most 


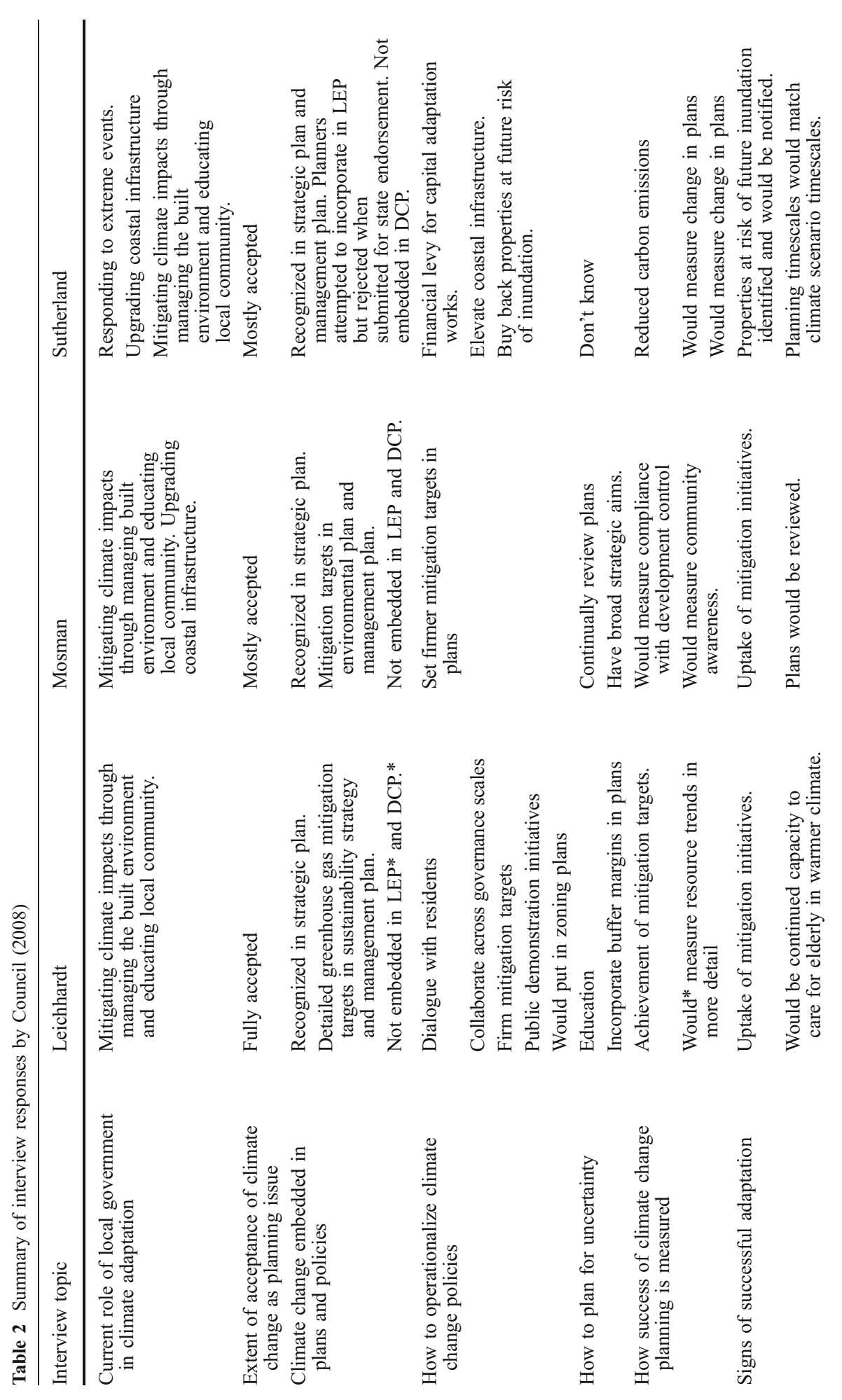



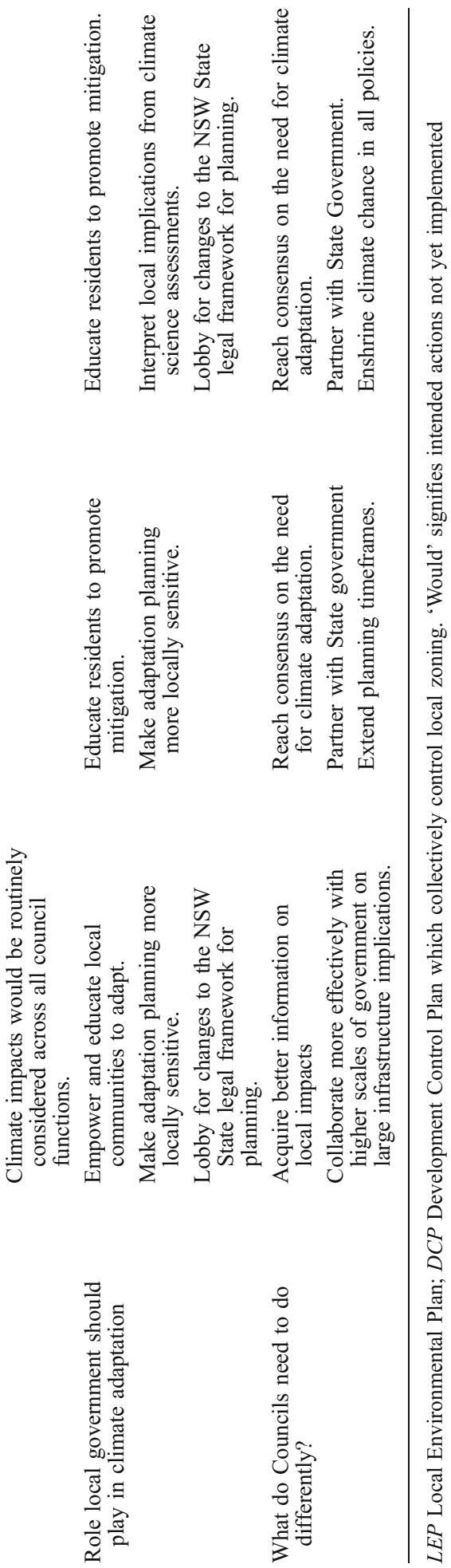
participants indicated that they had not considered adaptation at all prior to the interview. One rare example was the following:

.... at the moment we're developing a system of cycleways along Woolooware Bay... Some of those are upgrade structures and...we've identified those as being potentially vulnerable to climate change, in particular sea level rise. It may mean that we need to redesign future components of that so that they're not vulnerable.

When asked specifically about adaptation compared with mitigation, five key challenges were raised: leadership, competing priorities, planning process, information constraints and institutional constraints, which are discussed in the next section.

\subsection{Leadership}

Most of the participants acknowledged that planning needs to address climate change in a local government context. However, the importance of climate adaptation, rather than mitigation, varied between councils. This was mostly due to the priority placed on climate change by the leaders of each council. For example, some participants saw it as an utmost priority

It's really vital that our councillors want to be seen to be a leader in this area and would regard that our place-based planning needs to have a vision for the prospect of climate change.

Throughout the interviews it was clear that the opinions and value system of the mayor in particular, as well as the CEO or general manager, made a strong difference as to the opinions held by other participants. That said, there were several incidences where participants held contrasting positions to senior mangers or councillors which they were prepared to express in confidence. However, in some cases resistance was expressed to including climate change in the planning agenda:

I don't know that that's really reflected in the planning that we're doing at the moment. I think there's still an element of hope it won't happen.

While it is important to note some residual resistance to acknowledging climate change in general, overall there was a pervasive recognition of climate change as at least relevant for planning processes to consider, and hence there was sufficient recognition of the issue for it to be pushed onto the planning agenda.

\subsection{Competing priorities}

It was evident from interviews that adaptation represents only one area of priority amongst other competing interests for local government planning. This may account for some of the aforementioned reluctance to embrace the issue - such sentiments may not necessarily reflect outright scepticism, but rather feelings that the local government has more immediate issues with which to contend. These competing priorities arise from many sources, including the different perspectives and areas of operation among council staff and elected officials.

We're involved in everything from babies to bitumen and the request for more funding just comes in on a daily basis. We're not about to start throwing large sums of money at building extraordinary fortifications just in case the sea level rises. 
The importance of climate adaptation is also influenced considerably by how the issue is framed. For example, to the extent that it is viewed as a public safety issue or a development issue, it may have greater resonance within local government. Generally, interview respondents reported climate change as being seen largely as one environmental issue alongside such topics as pollution and water quality. For example, one interviewee commented:

...our environmental officers... have a better idea of what's going on with climate change and some other part of council like development assessment planners might not have as big an idea of what climate change issues are about because we're closer to [issues regarding] the people like developers. At present they don't really care about climate change.

This comment stands in contrast with the broader view that climate change and adaptation is in fact an important issue for planning. However, it also suggests that in some cases, knowledge and responsibility for tracking and responding to climate change is not evenly distributed across local government departments. In the case study councils, climate change was conceptualized as an environmental issue. For this reason, dealing with it was assigned to the environment department, along with waste management and pollution control. Exceptions to this tendency were found among council engineers, who in many cases mentioned sea level rise when discussing local climate and coastal hazard management.

\subsection{Planning process}

\subsubsection{Strategic planning and land-use planning}

Across all three case study councils, interview participants emphasised that climate change was part of their strategic plan in some form, either specifically or grouped as one of a suite of other environmental issues. This demonstrates that climate change is being considered in the guiding strategies of the three councils to varying degrees. However the focus was on mitigation, more so than adaptation. For example, as one interviewee stated,

Our strategic plan ...[has]... a section..., 'reduced greenhouse gas emissions'. A lot of that was to do with climate change. That's from the community...as a council, we respond to this, it flows down into our management plan....

Beyond strategic plans, the extent to which climate change was incorporated into operational plans varied considerably. For example one council had a sustainability strategy which specified greenhouse reduction targets in different areas around council:

... [We] have these targets that feed down from our strategic plan to our ... Management Plan, so they can be monitored. So there's specific targets for greenhouse gas reductions.

While climate change had appeared on the planning agenda, it had made little impact on development control and zoning plans. For example, at the time of the interviews, there was a lack of attention to climate change (either adaptation or mitigation) in Local Environmental Plans which frustrated several participants. For example,

I think council have accepted it as an issue for planning but we're still stuck... we need to...make this something that we have to adhere to. Like to put it in our LEP and actually make some guidelines... 
An over-riding theme of the interviews was that councils were still in the process of coming to terms with climate change, still developing plans and a long way from implementing them. When asked about how they might apply their policies regarding climate adaptation, the most common response was that participants simply didn't know how to go about it.

I don't know... how do you operate policy? I suppose, if I look at sea-level rises, I suppose we're trying to deal with that through our ...planning study.... But... operationalised policies is a bit of a different thing. I don't know how far advanced a lot of other organisations are with respect to that.

This quote draws attention to the fact that these challenges are not only faced by local governments, but by a broader range of organisations.

\subsection{Information constraints}

Participants identified a lack of useful, credible and relevant information about the nature of the climate risk to which they must adapt to be a key barrier for planning for climate change. This issue is captured in the following quote:

I guess there are some gaps in the knowledge - there are some issues that I'm not exactly aware of. We do talk about rise in sea levels and things like that but we're not really mapping those types of issues and I think we could respond to some of those issues a bit better, getting out a bit more data and research...

As such, a key process to incorporate climate change into planning process was to improve the information base for key climate adaptation issues. Increased intensity in storm events and the potential for sea-level rise and storm surge were noted as potential concerns for some councils. One council had made significant progress in this regard, in the form of a two-dimensional flood level study (see Box 1).

At the time of the interviews, engineers were undertaking a two-dimensional flood-level modelling study to calculate revised storm surge levels by incorporating a margin to allow for predictions of sea-level rise and more intense storm events:

We're also doing a estuary planning level study... which is working out storm surge levels around the foreshore based on a modelling of the whole harbour...it just recommends levels to build above and it has a built-in climate change factor...

The study involved working closely with climate scientists to provide access to the best available science, which was then applied to generate locally-relevant estimates of potential inundation.

The more that information was specific, the more powerful this became in terms of making a case for adaptation through planning. Again, sea-level rise represents an example where the impacts of climate change can be mapped and provide an argument for adaptation:

...we put...various reports to council - and sea-level rise is one of the best ones because we had a number that we could go with. We mapped that number and it just showed on a map exactly what the potential impacts of that were. So they could see in an instant what it was...

Of particular note was the desire for so called 'concrete' information, such as identifying tangible hazards in the form of particular parks or residential areas. This leads to another process issue for planning for climate change in the form of getting specific about the nature of planning challenges and how to respond to them. 
Box 1 Addressing knowledge gaps: examples of sea level rise and storm surge effects

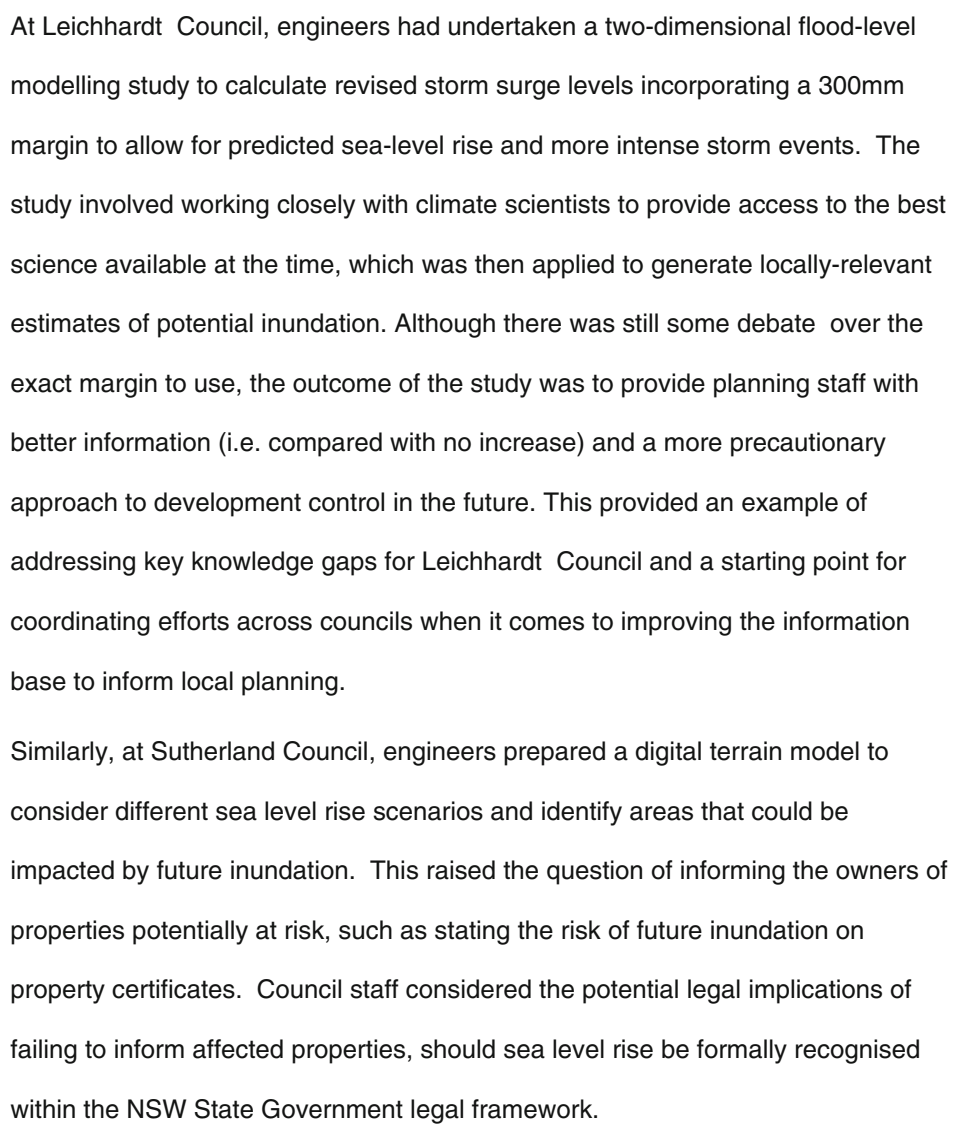

\subsection{Institutional constraints}

In the Sydney coastal council region, municipalities have a legislated responsibility for incorporating hazard management into planning, for hazards such as flooding and bushfires. However, the institutions underpinning this responsibility are largely developed and maintained by the Government of New South Wales, which at the time of the interviews, did recognize a changing climate but had not translated this recognition into updated policies or processes relating to local planning. This was particularly noted by participants when discussing sea level rise. Councils had the option of voluntarily including a margin for sea level rise; however this was hard to justify to competing planning interests without endorsement from a higher authority. As one participant explained:

....in terms of adapting to climate change we feel that we can only take it so far and we can't take it any further....We acknowledge the problem... but until there is a federal or state [decision]... to come out and say plan on a 50 year or a 100 year time horizon based on this degree of impact, we can't get off first base with flooding. 
So, in principle, councils can be more conservative in their planning than they are required to by state flood policy guidelines. However without the legal basis for adjusting local environmental planning in terms of climate change, it is difficult to do so in the face of competing planning interests.

In response to the limited provision to adapt to climate change through existing planning processes, council staff recognised the importance of lobbying for revising those processes, as one participant explained:

...the planning [instruments]... affect what kind of things are being allowed to happen in

your immediate area...but obviously there is the state. Well then we have a lobbying

role... it's lobbying the...government levels that are changing those controls

In this way, local government staff didn't see themselves as passive agents to implement state directives. Rather they saw themselves as grass roots agents of change who educated and empowered local communities and lobbied for institutional change when the planning architecture was constrained.

\section{Discussion}

The opportunities and constraints associated with local government adaptation efforts in the Sydney metropolitan region reflect a range of challenges with respect to how Australia has structured its national adaptation efforts. At the institutional level, Australia's efforts to facilitate adaptation have largely targeted the deficiency of knowledge and information regarding future climate change, vulnerability, and appropriate adaptation options. For example, the federal government has invested in the formation of adaptation research institutes such as the CSIRO Climate Adaptation Flagship and the National Climate Change Adaptation Research Facility. In addition, Preston and Kay (2010) observe that much of Australia's investments in adaptation to date have been in the form of scientific and technical assessment at the local level. Provisioning such information has resulted in a range of climate change risk assessments as well as risk management and adaptation guidance for local government (AGO 2006; DCCEE 2010). There are now dozens of local governments throughout Australia that are more aware of climate change risks and have identified a broad range of management responses. This represents a significant step forward yet also raises further questions on how to finance adaptation actions and implement the changes to planning frameworks which emerged as a key finding of this paper.

In theory and in practice, local government is identified as the closest level of government to community action. It is the scale at which the majority of development applications are processed, where most waste is managed and the health of the population is monitored (Brown 1997). However this proximity presents key challenges for local governments. The councils presented in this research saw themselves as educators and implementers of adaptation, yet were mindful to avoid pushing their communities too far.

The three main barriers recognised in the adaptation literature -lack of information, lack of resources and institutional limitations- were clearly evident in the case study councils. The manner in which councils addressed these existing concerns is insightful for other locations. In terms of lack of information, it is important to emphasise that the need for information varies not only due to the adaptation issue in question as argued by Dessai et al. (2005) but also due to the specific location, priorities and existing capacity of different 
councils. Our findings show that, in the case of sea-level rise and storm surge implications for planning, the information needs are quite specific and can be addressed through detailed hazard mapping in partnership with external technical support to provide best available estimates. In other instances, such as the effect of climate change on bushfire risk, councils did not need further detailed information. A workshop on this topic was sufficient for them to recognise that the frequency and intensity of this hazard may increase, but their information needs remain essentially unchanged (Smith et al. 2008b). An important implication of this research is to promote policy interventions which enable local governments to distinguish between the information needs of different types of climate hazards, so that they can prioritise their needs effectively.

The case study provides additional insights into the recognised constraint of institutional limitations. Two distinct sources of institutional limitations were evident in this study: those stemming from council internal structures and those occurring at higher levels of government. The most acute internal limitation, noted across each of the three case study councils, was a strong tendency to assign climate adaptation (along with mitigation) to the environment section of the council. This stems from a legacy of thinking of climate change as an environmental issue. The challenge for local government is to recognise climate adaptation as a cross-sectoral issue. This was starting to occur in some of the case study councils between the environment and water sections, with engineers considering the implications of flood and storm surge events. Institutional 'silos' are a historic problem, and climate adaptation is a renewed reason to address the challenge of cross-sectoral integration within councils (Critchley and Scott 2005).

The second type of institutional problem is much harder to address, namely the institutional context in which councils function. As Naess et al. (2005) demonstrate, councils frequently fulfil the role of implementing actions defined at higher scales, with little room to manoeuvre. Therefore, a lack of attention to climate change at the national and state levels leads to a lack of attention to climate adaptation at the local level (Amundsen et al. 2010). In our case study, this issue was most acute in regards to land use planning. Interviews with planners made it clear that a key flaw in the planning frameworks they use was that they assumed a stable climate, thus substantially constraining any attempt to incorporate climate adaptation into municipal planning.

Yet our case study extends this picture in showing that, by identifying and specifying the limitations of higher level institutional arrangements, it is possible for local levels to argue a basis for change at the national level. This process moves from adaptation science to the political domain, as happened following the empirical research presented here. One of the partners in the research, namely the Sydney Coastal Councils Group, lobbied the Government of New South Wales to change the planning laws by which local governments operate in order to recognise sea level rise in the planning system and enable municipalities to plan for this climate impact. Without attributing causality directly to either this research or the political lobbying of SCCG, it is important to note that the planning framework was amended by the state government following this project such that sea level rise and guidelines were developed for integrating sea level rise into municipal planning frameworks. These guidelines include considering future development assessment against hazard lines reflecting a projected sea level rise of $40 \mathrm{~cm}$ by 2050 and $90 \mathrm{~cm}$ by 2100 from 1990 mean levels (Department of Planning 2010). What this demonstrates is that a scientifically sound research combined with local political lobbying can lead to policy change at higher scales.

The case study also draws attention to the complicated nature of place-based planning which is raised in the literature on CBEP. This literature emphasises the multiplicity of 
intersecting communities which contest each other (Lane and McDonald 2005). In the case study presented here, this manifested itself as competing planning priorities. What our findings show of relevance to other locations is that, in any given local authority, the planning agenda is usually already full. Presenting the need for climate adaptation competes for space amongst other needs which can seem more pressing for local councils such as road maintenance and child care facilities. This issue of competing priorities is inherently tied to the issue of resources (Critchley and Scott 2005). Even if the need for climate adaptation is acknowledged in the conceptual realm of strategic planning, it may be underrepresented when it comes to allocating scarce resources.

The political nature of local government means that all decisions, including climate adaptation, are affected by political interests and competing preferences vying for support at the municipal scale (Keen et al. 2006). Our findings emphasise the role of leadership support for adaptation in the propensity to respond to climate change through local planning. Brown (2005) notes that leadership on sustainability matters in local government can come from a wide range of levels - from junior staff to senior executives and elected representatives. Therefore, climate adaptation can be driven from within the ranks. However, it is important to recognise that allocating adequate resources and setting goals is strongly tied to the platforms of elected officials, which means that the support, or lack of it, from political leaders can enable or stifle climate adaptation at the local scale. In some ways we are seeing at the local scale an echo of the international political debates held amongst national leaders and scientific communities such as the IPCC. Some local leaders are pushing for action whilst others are stalling based on claims of inadequate information, or denying the need for local adaptation in the face of other interests. Where local leaders considered climate change to be a pressing issue, resources were available and information needs were addressed. Above all, support from senior leaders is necessary to develop a coordinated approach to climate adaptation through implementing relevant tools and processes across internal divisions (Critchley and Scott 2005).

\section{Conclusion}

Local government is at the coal face of adaptation in the context of place-based vulnerability where impacts are experienced in the forms of inundation, bushfires, heatwaves and rising sea levels. To adequately plan and adapt to these challenges, local government needs to show leadership in three core areas. First, to move beyond mitigation to include a focus on adaptation in practical terms; second, to push for reform at higher levels of government to enable changes in the planning frameworks which currently hinder local adaptation; and third, to embed climate adaptation into a wider range of council functions.

Due to the competing interests associated with local place-based planning and the politicised nature of local government, it can not be assumed that addressing the surface constraints alone (such as lack of information and resources) will significantly enable local adaptation in the face of political resistance. It has taken local government a long time to embed climate mitigation into policy and practice, so it is not surprising that movement towards climate adaptation has been slow. The need for climate adaptation was being taken up, to varying degrees, by strategic planners in each of the case study municipalities, but not by land-use planners at the time of data collection. Moreover, a key flaw in the planning frameworks in use was that they assumed a stable climate, with no mechanisms established to facilitate adaptation. Following this research and 
political lobbying for a better policy platform on behalf of project partners, the planning framework has been altered in New South Wales to recognise sea level rise. This demonstrates that the institutional context for achieving climate change through local planning can be improved when research is used to assist local governments to lobby higher levels of government. Only by gaining acceptance in the political arena can climate adaptation gain traction on the planning agenda.

Acknowledgements This research was funded by the CSIRO Climate Adaptation Flagship and the Australian Government Department of Climate Change. Thanks to the staff and Councillors of Leichhardt, Mosman and Sutherland Councils who participated in this research.

Open Access This article is distributed under the terms of the Creative Commons Attribution Noncommercial License which permits any noncommercial use, distribution, and reproduction in any medium, provided the original author(s) and source are credited.

\section{References}

Adger WN (2003) Social aspects of adaptive capacity. In: Smith JB, Klein RJT, Huq S (eds) Climate change, adaptive capacity and development. Imperial College, London

Adger WN, Kelly PM (1999) Social vulnerability to climate change and the architecture of entitlements. Mitig Adapt Strateg Glob Change 4:253-266

Adger WN, Eakin H, Winkels A (2009) Nested and teleconnected vulnerabilities to environmental change. Front Ecol Environ 7(3):150-157

Agrawal A (2008) The role of local institutions in adaptation to climate change. In: Papers of the Social Dimensions of Climate Change Workshop. The World Bank, Washington DC, March 5-6, 2008

Agrawal A, Gibson CC (1999) Enchantment and disenchantment: the role of community in natural resource conservation. World Dev 27(4):29-649

Amundsen H, Berglund F, Westskog H (2010) Overcoming barriers to climate change adaptation: a question of multilevel governance? Environ Plann C 28(2):276-289

Australian Greenhouse Office (AGO) (2006) Climate change impacts and risk management: a guide for business and government. Australian Government, Canberra

Berrang-Ford L, Ford JD, Paterson J (2011) Are we adapting to climate change? Glob Environ Change $21: 25-33$

Boydell EW 2010 Adaptation to climate change in practice: learning from a local government case study. Dissertation, Australian National University

Brackertz N, Kenley R (2002) A service delivery approach to measuring facility performance in local government. Facilities 20(3/4):127-135

Brown V (1997) Managing for local sustainability: policy, problem-solving, practice and place. Department of Environment Sport and Territories, Canberra

Brown VA (2005) Leadership in the local government sector: working from the inside out. In: Hargroves K, Smith MH (eds) The natural advantage of nations: business opportunities, innovation, and governance in the 21 st century. Earthscan, London

Commission of the European Communities (CEC) (2007) Adapting to climate change in Europe - options for EU action SEC 849, Brussels

Council of Australian Governments (COAG) (2007) National climate change adaptation framework. Department of the Prime Minister and Cabinet, Canberra

Crabbé P, Robin M (2006) Institutional adaptation of water resource infrastructures to climate change in Eastern Ontario. Climatic Change 78(1):103-133

Critchley V, Scott J (2005) Changing governments: councils embracing the precautionary principle. In: Keen M, Brown V, Dyball R (eds) Social learning in environmental management: towards a sustainable future. Earthscan, London

Cutter SL, Mitchell JT, Scott MS (2000) Revealing the vulnerability of people and places: a case study of Georgetown County, South Carolina. Ann Assoc Am Geogr 90(4):713-737

Department of Climate Change and Energy Efficiency (DCCEE) (2010) Climate change adaptation actions for local government. Department of Climate Change and Energy Efficiency, Canberra 
Department of Communities and Local Government (DCLG) (2010) Communities and local government departmental adaptation plan. Department of Communities and Local Government, London

Department of Planning (2010) NSW Coastal Planning Guideline: Adapting to Sea Level Rise. New South Wales Government, Sydney ISBN 978-1-74263-035-9

Dessai S, Lu X, Risbey JS (2005) On the role of climate scenarios for adaptation planning. Glob Environ Change 15(2):87-97

Dovers SR, Hezri AA (2010) Institutions and policy processes: the means to the ends of adaptation. Wiley Interdisciplinary Reviews: Clim Change 1(2):212-231

Ebi KL, Semenza JC (2008) Community-based adaptation to the health impacts of climate change. Am J Prev Med 35(5):501-507

Ford JD, Berrang-Ford L, Paterson J (2011) A systematic review of observed climate change adaptation in developed nations. A letter. Climatic Change 106:327-336

Hajer M (2003) Policy without polity? Policy analysis and the institutional void. Policy Sci 36:175-195

Hajer M, Versteeg W (2005) Performing governance through networks. Euro Polit Sci 4:340-347

ICLEI Canada (2010) Changing climate, changing communities. Guide and workbook for Canadian municipalities. ICLEI Canada, Toronto

ICLEI Oceania (2008) Local government climate change adaptation toolkit. Cities for climate protection Australia adaptation initiative. ICLEI Oceania, Melbourne

Ivey JL, Smithers J, De Loë RC, Kreutzwiser RD (2004) Community capacity for adaptation to climateinduced water shortages: linking institutional complexity and local actors. Environ Manage 33(1):36-47

Keen M, Mahanty S, Sauvage J (2006) Sustainability assessment and local government: achieving innovation through practitioner networks. Local Environment 11(2):201-216

Lane MB, Corbett T (2005) The tyranny of localism: Indigenous participation in community-based environmental management. J Environ Policy Plann 7(2):141-159

Lane MB, McDonald G (2005) Community-based environmental planning: operational dilemmas, planning principles and possible remedies. J Environ Plann Man 48(5):709-731

Li TM (2002) Engaging simplifications: community-based resource management, market processes and state agendas in upland southeast Asia. World Dev 30(2):265-283

Measham TG, Lane MB (2010) Community-based environmental planning. In: Warf B (ed) Encyclopedia of geography. SAGE, Thousand Oaks

Ministry for the Environment (ME) (2008) Climate change effects and impacts assessment. A guidance manual for local government in New Zealand, 2nd edn. New Zealand Ministry for the Environment, Wellington

Moser SC (2010) Now more than ever: the need for more societally relevant research on vulnerability and adaptation to climate change. Appl Geogr 30(4):464-474

Mukheibir P, Ziervogel G (2007) Developing a Municipal Adaptation Plan (MAP) for climate change: the city of Cape Town. Environ Urban 19(1):143-158

Naess LO, Bang G, Eriksen S, Vevatne J (2005) Institutional adaptation to climate change: flood responses at the municipal level in Norway: adaptation to climate change: perspectives across scales. Glob Environ Change 15(2):125-138

National Climate Change Adaptation Research Facility (NCCARF) (2010) International Climate Change Adaptation Conference: Climate Adaptation Futures: Preparing for the unavoidable impacts of climate change 29 June-1 July 2010, Goldcoast, Australia, http:/www.nccarf.edu.au/conference2010/ cited 15 Dec 2010

National Research Council (NRC) (2010) Adapting to the impacts of climate change. Panel on adapting to the impacts of climate change. National Academies of Science, Washington, DC

Pini B, Wild River S, McKenzie FMH (2007) Factors inhibiting local government engagement in environmental sustainability: case studies from rural Australia. Aust Geogr 38(2):161-175

Preston BL, Kay RC (2010) Managing climate risk in human settlements. In: Jubb I, Holper P, Cai W (eds) Managing climate change: papers from the Greenhouse 2009 Conference. CSIRO Publishing, Melbourne

Preston BL, Smith T, Brooke C, Gorddard R, Measham TG, Withycombe G, McInnes K, Abbs D, Beveridge B, Morrison C (2008) Mapping climate change vulnerability in the Sydney Coastal Councils Group. Prepared for the Sydney Coastal Councils Group and the Australian Greenhouse Office. CSIRO, Melbourne

Preston BL, Brooke C, Measham TG, Smith TF, Gorddard R (2009) Igniting change in local government: Lessons learned from a bushfire vulnerability assessment. Mitig Adapt Strateg Glob Change 14(3):251-283

Preston BL, Westaway RM, Yuen EJ (2011) Climate adaptation planning in practice: an evaluation of adaptation plans from three developed nations. Mitig Adapt Strateg Glob Change 16(4):407-438

QSR (2010) NVivo Software. http://www.qsrinternational.com/products_nvivo.aspx. Cited 12 Dec 2010

Reid H, Cannon T, Berger R, Alam M, Milligan A (2009) Community-based adaptation to climate change. Participatory Learning 60, International Institute for Environment and Development, Russell Press, Nottingham

Repetto R (2008) The climate crisis and the adaptation myth. Working Paper 13, Yale School of Forestry and Environmental Studies, New Haven 
Richardson G (2010) Adapting to climate change: an introduction for Canadian municipalities. Natural Resources Canada, Ottawa

Scott JC (1998) Seeing like a state: how certain schemes to improve the human condition have failed. Yale University Press, New Haven

Selman PH (1996) Local sustainability: managing and planning ecologically sound places. Paul Chapman Publishing, London

Selman P (1999) Three decades of environmental planning: what have we really learned? In: Kenny M, Meadowcroft J (eds) Planning sustainability. Routledge, London

Shaw A, Sheppard S, Burch S, Flanders D, Wiek A, Carmichael J, Robinson J, Cohen S (2009) Making local futures tangible- Synthesizing, downscaling, and visualizing climate change scenarios for participatory capacity building. Glob Environ Change 19(4):447-463

Smith TF, Brooke C, Measham TG, Preston B, Gorddard R, Withycombe G, Beveridge B, Morrison C (2008a) Case studies of adaptive capacity: Systems approach to regional climate change adaptation strategies. CSIRO Climate Adaptation Flagship, Sydney

Smith TF, Preston B, Gorddard R, Brooke C, Measham TG, Withycombe G, Beveridge B, Morrison C (2008b) Regional workshops synthesis report: Sydney Coastal Councils' vulnerability to climate change: Part 1. CSIRO Climate Adaptation Flagship, Sydney

Smith TF, Preston B, Brooke C, Gorddard R, Abbs D, McInnes K, Withycombe G, Morrison C, Beveridge B, Measham TG (2009) Managing coastal vulnerability: new solutions for local government. In: Moksness E, Dahl E, Støttrup JG (eds) Integrated coastal zone management. Wiley-Blackwell, West Sussex

Smith JB, Vogel JM, Cruce TL, Seidel S, Holsinger HA (2010) Adapting to climate change: a call for federal leadership. Pew Center on Global Climate Change, Arlington

Snover AK, Whitely Binder L, Lopez J, Willmott E, Kay J, Howell D, Simmonds J (2007) Preparing for climate change: a guidebook for local, regional, and state governments. ICLEI-Local Governments for Sustainability, Oakland

Swart R, Biesbroeck R, Binnerup S et al. (2009) Europe adapts to climate change: comparing national adaptation strategies. Partnership for European Environmental Research, Helsinki

Tompkins EL (2005) Planning for climate change in small islands: Insights from national hurricane preparedness in the Cayman Islands: adaptation to climate change: perspectives across Scales. Glob Environ Change 15(2):139-149

Tompkins EL, Adger WN (2004) Does adaptive management of natural resources enhance resilience to climate change? Ecology and Society 9(2):10 [online] http://www.ecologyandsociety.org/vol9/iss2/art10/

Turner BL, Kasperson RE, Matson PA, McCarthy JJ, Corell RW, Christensen L, Eckley N, Kasperson JX, Luers A, Martello ML, Polsky C, Pulsipher A, Schiller A (2003) A framework for vulnerability analysis in sustainability science. Proc Natl Acad Sci USA 100(14):8074-8079

Walker B, Carpenter S, Anderies J, Abel N, Cumming GS, Janssen M, Lebel L, Norberg J, Peterson GD, Pritchard R (2002) Resilience management in social-ecological systems: a working hypothesis for a participatory approach. Conservation Ecology 6(1):14 [online] http://www.consecol.org/vol6/iss1/art14/

Wild River S (2006) Australian local government attempts to deliver beneficial environmental outcomes. Local Environment 11(6):719-732 